\title{
"Diffusion Ruby" Proves to Be SYNTHETIC RUBY OVERGROWTH ON Natural CORUNDUM
}

\author{
By Christopher P. Smith
}

A relatively new production of red corundum, reportedly from Bangkok, has been offered for sale in recent years. Although the producers claimed that these stones were red diffusion-treated corundum (i.e., a shallow coloration induced by the lattice diffusion of chromium), the surface layer is actually a synthetic ruby overgrowth on natural colorless to near-colorless corundum. The overgrowth layer, after recutting, typically ranged from $<0.1$ to $0.3 \mathrm{~mm}$ thick. This material can be distinguished from red lattice diffusion-treated corundum by the presence of a boundary plane and two different types of inclusion features: those that occur in the natural corundum core and those present only in the synthetic overgrowth. This product demonstrates that as treatment techniques continue to evolve, the distinction between natural, treated, and synthetic corundum may become increasingly difficult to define.

A relatively new product seen occasionally at gem shows since 1998 has been marketed as "Diffusion Ruby" (figure 1). When the author examined several specimens of this strongly colored red corundum, it became clear that the shallow red coloration was not the result of a diffusion treatment-that is, the diffusion of chromium into the lattice of the host corundum (lattice diffusion) to induce a shallow red color layer at the surface of an otherwise pale or near-colorless sapphire. Rather, it was an overgrowth of synthetic ruby on top of colorless to near-colorless natural corundum. A similar product was grown experimentally by J. Lechleitner of Innsbruck, Austria, in the early 1980s
(Bank, 1983; Schmetzer and Bank, 1988); however, this material was never produced in commercial quantities. The present article describes the gemological characteristics that will distinguish this new commercial product from red lattice diffusion-treated corundum as well as from natural rubies.

\section{MATERIALS AND METHODS}

In the course of conversations with vendors who were selling stones labeled as "Diffusion Ruby," the author made a cursory examination of approximately 50 specimens, macroscopically and with a $10 \times$ loupe. Eleven faceted samples were selected from two of the vendors as those best representing the various characteristics observed in the larger group. They ranged from 0.80 to $1.84 \mathrm{ct}$ (see, e.g., figure 1). One of these vendors indicated that his supplier was the originator of the treatment, which was done in Bangkok (J. Boyle, pers. comm., 1998).

Three of the samples were subsequently repolished to permit analysis of the surface layer and the main body of the stones. One sample was recut and repolished into a $2 \mathrm{~mm}$ slice, to produce parallel windows that bisected the stone along its length, whereas the other two samples were repolished at one end of each stone to more clearly differentiate the natural core from the synthetic outer layer.

\footnotetext{
ABOUT THE AUTHOR

Mr. Smith is managing director of the Gübelin Gem Lab Ltd. in Lucerne, Switzerland.

Acknowledgments: The author would like to thank Mr. Jay Boyle of Novastar, Fairfield, lowa, for providing some of the samples. Unless otherwise stated, all photographs are by the author. Gems \& Gemology, Vol. 38, No. 3, pp. 240-248.

(C) 2002 Gemological Institute of America
} 
All tests were conducted on all 11 samples. Standard gemological instrumentation was used to record the refractive indices, birefringence, optic character, pleochroism, and optical absorption spectra (desk-model spectroscope). Refractive index readings were taken on the table and pavilion facets. Specific gravity was determined hydrostatically. A binocular microscope, incorporating fiber-optic and other lighting techniques, was used to document the microscopic features. Color zoning and internal growth structures were analyzed with a horizontal microscope, a specially designed stoneholder, and a mini-goniometer attached to one of the oculars on the microscope, employing the methods described by Schmetzer (1986), Kiefert and Schmetzer (1991), and Smith (1996). Laser Raman microspectrometry was performed using a Renishaw Raman System 2000 equipped with an argon-ion laser. Semi-quantitative to qualitative chemical analyses were taken on both table and pavilion facets by means of energy-dispersive X-ray fluorescence (EDXRF) spectroscopy performed on a Spectrace TN5000 system, using a program specially developed for the analysis of corundum. Infrared spectra in the region between 7000 and $400 \mathrm{~cm}^{-1}$ were taken with a PyeUnicam FTIR spectrometer using a diffuse reflectance unit.

\section{RESULTS}

Visual Appearance. When viewed face up with the unaided eye, all samples displayed a saturated red color (again, see figure 1). The color appeared relatively homogeneous, although closer inspection revealed that it was slightly uneven or patchy in some of the samples.

In contrast, when the samples were viewed face down (particularly over a white background, such as a piece of paper), all but two displayed uneven or patchy color distribution that correlated to the facet arrangement of the stones (see, e.g., figure 2).

The three samples that were repolished clearly revealed a saturated red coloration that was confined to a shallow surface-related layer, whereas the main body of the stone beneath this color layer was essentially colorless (figure 3).

Gemological Characteristics. The pleochroism, birefringence, optic character, and specific gravity of all samples were consistent with corundum in general (see, e.g., Webster, 1983; Hurlbut and Kammerling, 1991; Hughes, 1996).

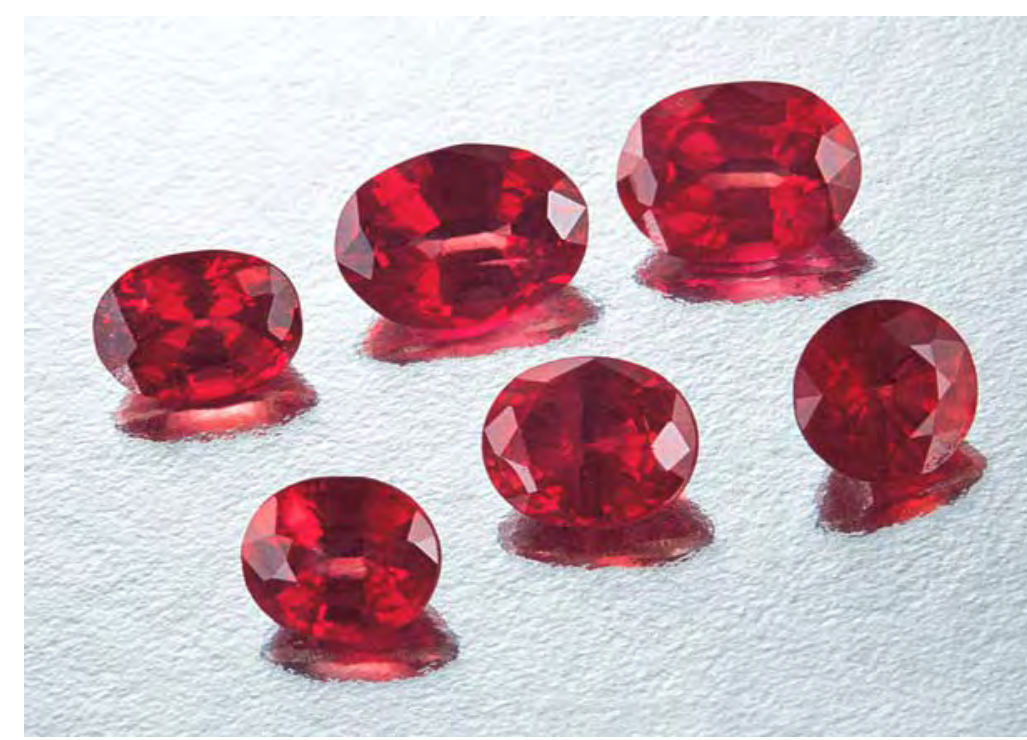

Figure 1. These strongly saturated red stones were marketed as "Diffusion Ruby." However, gemological testing revealed that they are actually the result of a synthetic ruby overgrowth onto colorless to nearcolorless natural sapphire. These six samples $(0.80-1.12 \mathrm{ct})$ are part of the group studied in detail for this report. Photo by Maha Tannous.

A few samples displayed typical corundum R.I. readings from the table facet (i.e., $\mathrm{n}_{\mathrm{o}}=1.760-1.761$, $\left.\mathrm{n}_{\mathrm{e}}=1.768-1.770\right)$, although the readings were less distinct than normal. Rather unexpectedly, most of the readings revealed an R.I. that was over the lim-

Figure 2. When viewed face down, most of the syntheticovergrowth corundum samples readily showed uneven coloration between adjacent facets. The degree of visibility, however, was very dependent on the thickness of the overgrowth layer. Photo by Maha Tannous.

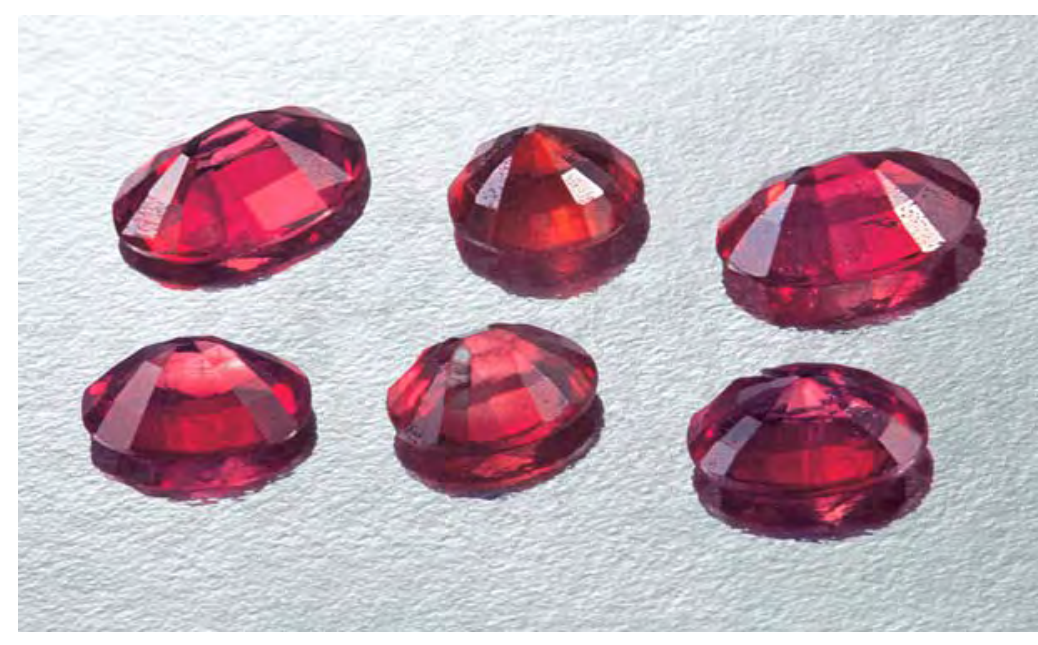




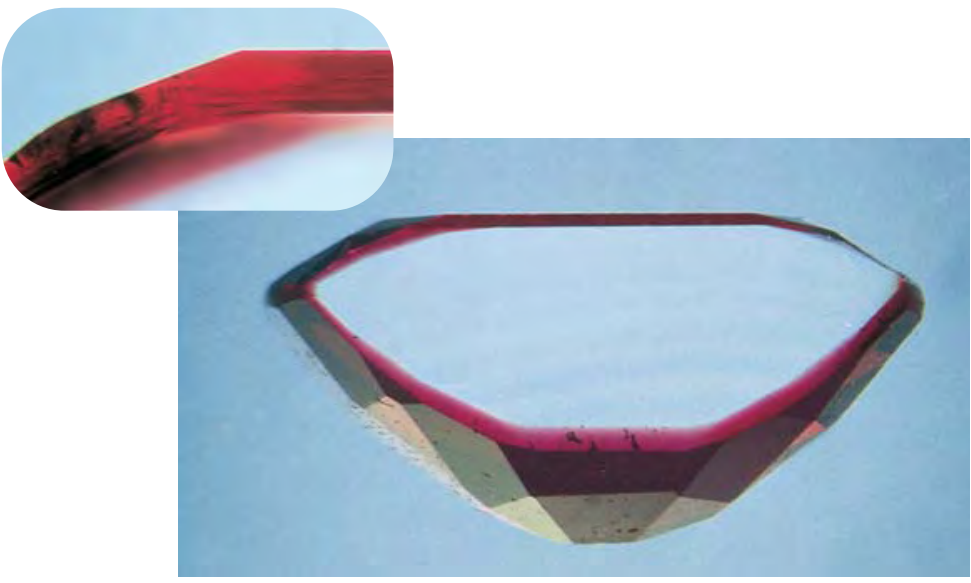

Figure 3. To better observe the overgrowth layer and the core, a $0.86 \mathrm{ct}$ sample was recut and repolished into a 2-mm-thick slice along the center of the length (approximately $6.5 \mathrm{~mm}$ ). The colorless core of the natural "host" and the deeply saturated red synthetic overgrowth layer are clearly evident. Inset: With higher magnification, the sharp, distinct boundary between the colorless core and the saturated red outer layer is readily seen. Magnified 40x.

its (OTL) of a standard refractometer (>1.81). All readings taken on the pavilion facets were OTL. The R.I. of the colorless "core" region in the recut and repolished thin slice revealed normal corundum readings of $\mathrm{n}_{\mathrm{o}}=1.760$ and $\mathrm{n}_{\mathrm{e}}=1.768$.

The absorption spectra of all samples were typical of ruby, both natural and synthetic (see, e.g., Liddicoat, 1989), and ranged from weak to very strong. In addition, all the samples were inert to faint red when exposed to long-wave UV radiation. One stone also displayed faint orange fluorescent zones that were confined to the interior of the stone. All stones were inert to short-wave UV.

Figure 5. Many indentations or cavities at the surface of these stones extended the full depth of the overgrowth layer, down to but not beyond the boundary with the natural corundum. Typically, the walls of these indentations displayed a stepped morphology consistent with the formation of many small external crystal faces. Magnified 50x.

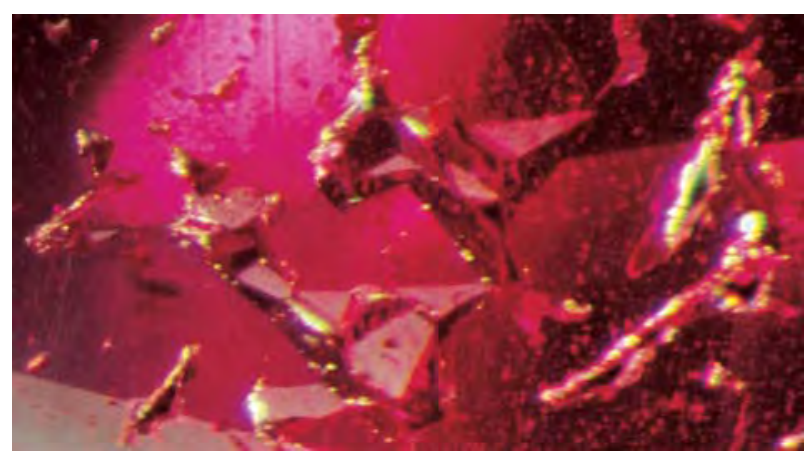

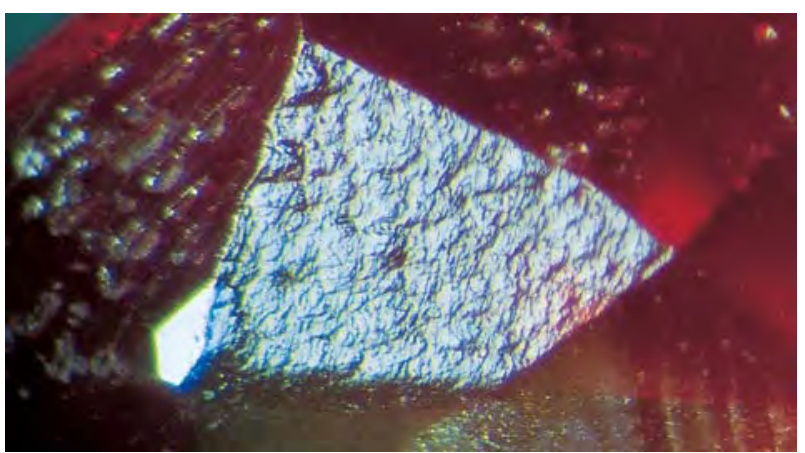

Figure 4. On several of the samples, areas of the original "skin" of the synthetic overgrowth layer remained at the surface. In reflected light, the surface topography of these areas shows characteristics of crystal growth, as opposed to the surface etching that would be expected for true red lattice diffusion-treated corundum. Magnified 28x.

Microscopic Features. Surface Features. Several of the samples retained areas of the original surface of the outer layer (see, e.g., figure 4), which had not been removed during repolishing. The contours of these areas were smooth and slightly undulating, as well as stepped with series of small, planar surfaces that resembled the development of multiple crystal faces. Also noted were several indentations or cavities, the walls of which revealed similar stepped planar surfaces (figure 5). These indentations were highly concentrated in some areas; they occasionally extended the full depth of the shallow outer layer, but never into the interior region.

Color Zoning and Internal Growth Features. The patchy color concentrations between adjacent facets

Figure 6. The uneven distribution of color was easily seen when the samples were immersed (here, in methylene iodide) and viewed with a diffused transmitted light source. Photo by Maha Tannous.

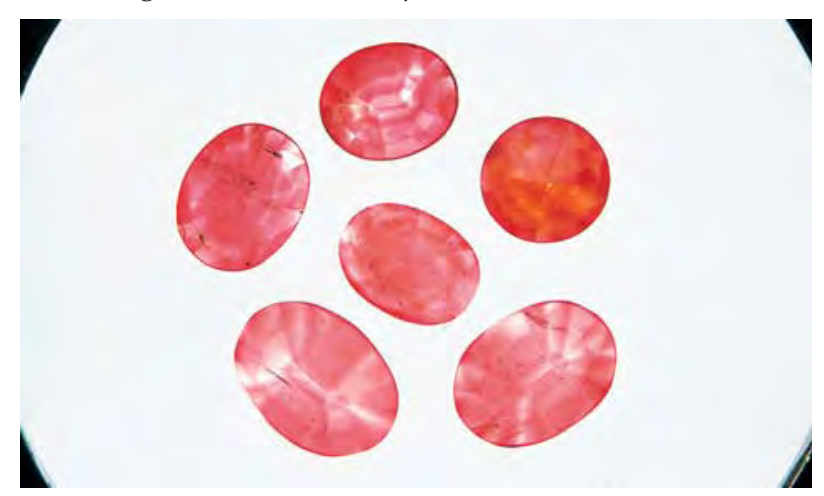




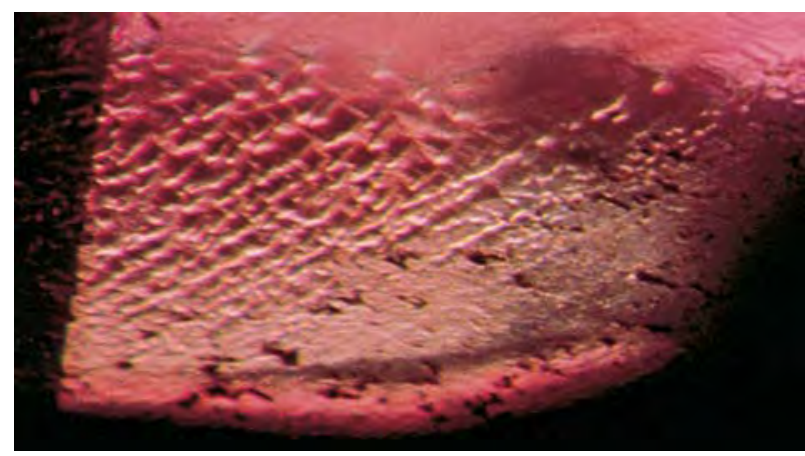

Figure 7. Within the overgrowth layer could be seen a distinctly mottled or roiled texture, which was related to the irregular growth formation. Magnified 38x.

seen in some samples with the unaided eye were even more apparent with magnification, especially with a diffused light source (using a standard diffuser plate or even a piece of tissue paper). With immersion (e.g., in methylene iodide) over a diffused light source, all samples clearly displayed uneven color concentrations between adjacent facets and facet edges (see, e.g., figure 6). In the three repolished samples, the demarcation between the saturated red surface-related layer and the colorless zone beneath it was even more dramatic (again, see figure 3).

In all samples, the red coloration halted dramatically at a boundary plane visible just below the surface. The "bleeding" of color between outer and inner regions that is typical of blue and red lattice diffusion-treated corundum (see, e.g., Kane et al., 1990; McClure et al., 1993; Hughes, 1996) was not evident in any of the samples. One sample also revealed a yellow-to-orange color zone confined to one area of its interior.

Other observations made more readily with immersion included irregular "roiled" or striated growth features within the shallow surface layer (figure 7). In contrast, the interiors of the stones showed subtle to prominent planar and angular sequences of internal growth structures composed of the basal pinacoid $c\{0001\}$, positive rhombohedron $r\{10 \overline{1} 1\}$, and combinations of various di-pyramidal growth planes. These features are typical of natural corundum.

Another distinctive feature visible with immersion-an image reminiscent of a series of steep mountainside contours (figure 8)-was created by the combination of the external surface of the synthetic overgrowth layer, the subsurface of the natural core, and the areas where the boundary plane intercepted the external surface. The author had not previously encountered such a feature in natural, diffusion-treated, or synthetic ruby.

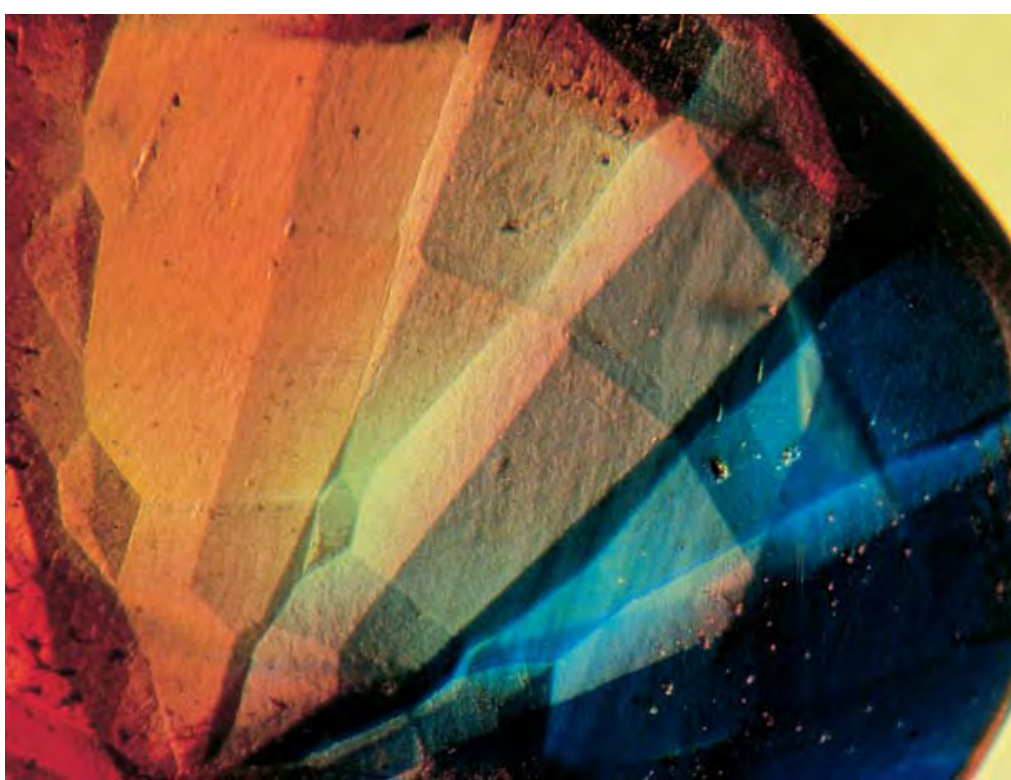

Figure 8. A unique characteristic noted with immersion and transmitted light in all the samples was an image that resembled a series of steep mountainside contours. Magnified 15×.

Inclusions. During microscopic examination, it became obvious that there were two different sets of inclusions in each sample, separated by the boundary plane. One set was concentrated along the boundary and within the thin outer layer; the other was present only in the interior of the gem.

The most significant inclusion features occurred at the boundary, which typically was accompanied by a high concentration of unidentified inclusions that were present in generally parallel, linear formations (figure 9). In some areas, these inclusions changed orientation but remained aligned with one

Figure 9. A high concentration of aligned inclusions occurred during the initial deposition of the synthetic overgrowth. As a result, these inclusions clearly demarcated the boundary between the host gemstone and the synthetic overgrowth. Magnified 22x.

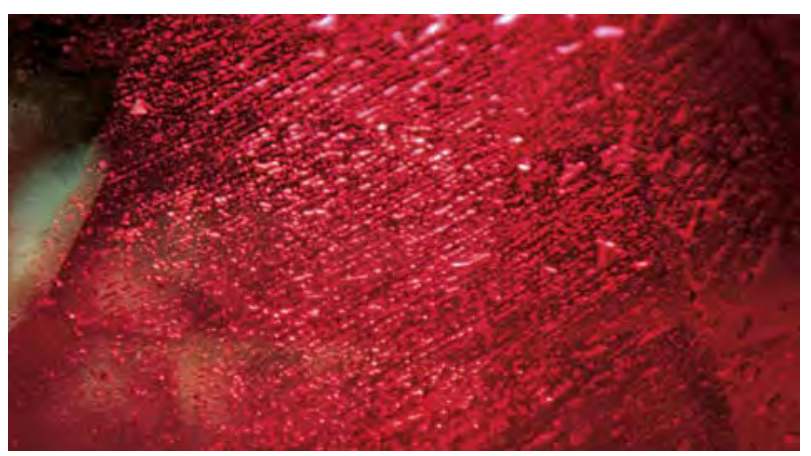



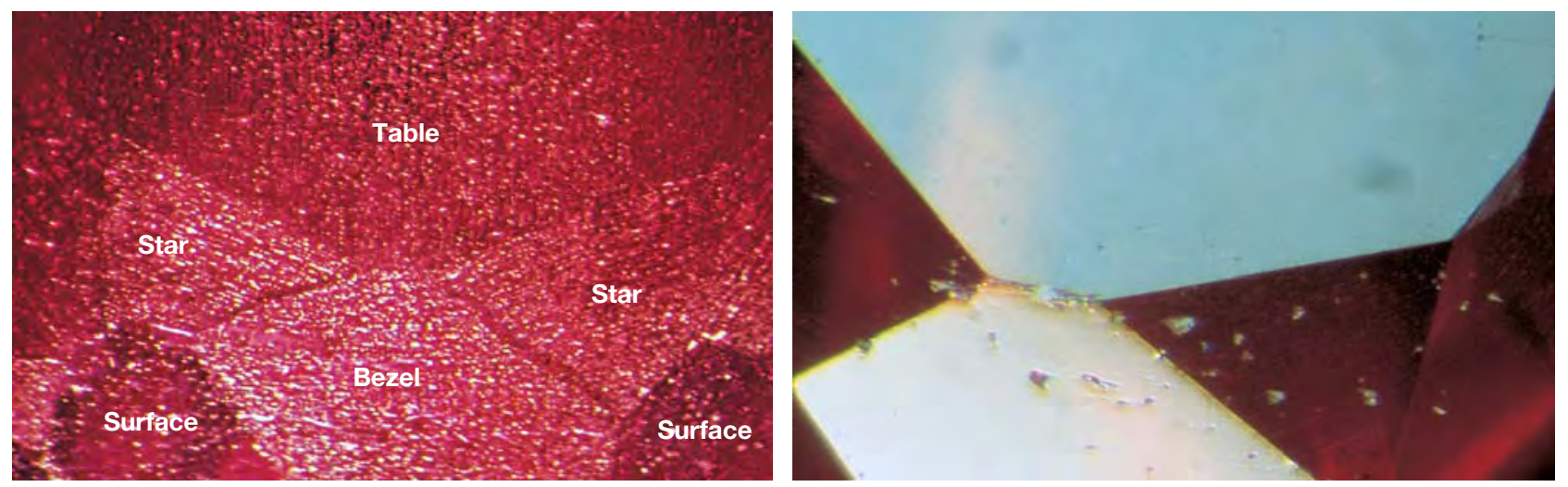

Figure 10. On the left, the table, bezel, and star facet arrangement of the faceted natural corundum core is clearly visible just below the surface of this $0.95 \mathrm{ct}$ sample. Also note the two surface areas devoid of aligned inclusions, where entire portions of the overgrowth layer have been polished away. On the right, this same area viewed with reflected light clearly shows that the external facet arrangement of the synthetic overgrowth layer (i.e., the surface of the stone) does not correspond to that of the natural corundum core. Magnified 32x.

another. The various angles created by the abrupt changes in orientation were not consistent within individual samples or between samples in this study; nor did they correlate to angles related to the formation of internal growth structures (see, e.g., Smith, 1996). Furthermore, geometric outlines resembling bezel, star, upper-girdle facets, and pavilion step facets were seen below the surface, where the aligned inclusions at the boundary plane changed directions (figure 10).

As a result of repolishing, the planar boundary did not occur at a uniform depth beneath every facet. In some areas of each sample, the red outer layer was less than $0.1 \mathrm{~mm}$ thick, whereas in other areas it was as much as $0.3 \mathrm{~mm}$ thick. In several of the samples, this boundary and the associated concentration of inclusions intercepted the surface of the stone (areas where repolishing had completely removed portions of the outer layer).

Turbid bluish white clouds could be seen throughout the outer layer, as well as along or just beneath the boundary, within the host sapphire plane. Sometimes these clouds were homogeneous in texture; other times they were distinctly mottled and uneven. Also observed in the outer layer were numerous pinpoint inclusions (figure 11).

A variety of inclusion features in the interior regions of the samples extended to, but not beyond, the boundary plane (figure 12). In addition, all samples showed evidence of high-temperature thermal alteration. These included altered remnants of rutile needles, platelets, and stringer formations, as well as apparently unaltered needle, platelet, and stringer formations of presumably hematite or ilmenite. Small crystalline inclusions, as well as series of negative crystals, were accompanied by altered and/or induced stress fractures. Most samples contained naturally occurring healed fractures, which further revealed evidence of thermal alteration.

Raman Analysis. Raman spectra of two repolished stones, taken specifically to analyze only the strongly colored outer layer above the boundary plane and the interior region of the samples, confirmed that in both areas the material was corundum, with Raman peaks located at 750,577 , and $419 \mathrm{~cm}^{-1}$ (see, e.g., Hänni et al., 1996; Williams et al., 1997).

Chemical Analysis. EDXRF revealed a significant variability in the chromium $\left(\mathrm{Cr}_{2} \mathrm{O}_{3}\right)$ concentrations (from less than 0.01 or "not detected" to $12.8 \mathrm{wt. \%}$ ) recorded from the table facet as well as from different sides of the pavilion on individual samples and from one sample to another. Analyses taken on facets where the shallow outer layer was present revealed 4.0-12.8 wt. \% $\mathrm{Cr}_{2} \mathrm{O}_{3}$. A rough general correlation could be made between the thickness of the outer layer and the $\mathrm{Cr}$ concentration (i.e., thinner layer, lower relative $\mathrm{Cr}$ concentration-thicker layer, higher relative $\mathrm{Cr}$ concentration). Chemical analyses taken on the interior regions of the repolished samples, as well as on facets of other samples where the outer layer had been removed by repolishing, did not reveal any detectable Cr. None of the analyses taken on the outer layers detected any sodium or heavy elements such as lead, platinum, tungsten, bismuth, molybdenum, or the like.

Infrared Spectroscopy. All of the spectra revealed the absorption characteristics of corundum between approximately 1500 and $300 \mathrm{~cm}^{-1}$ (see, e.g., Smith, 1995). No other absorption bands relating to struc- 
tural $\mathrm{OH}$ groups or other foreign mineral phases were seen.

\section{DISCUSSION}

Raman analysis proved that the outer layer of highly saturated red color was corundum (i.e., ruby). The synthetic origin of this outer layer/overgrowth was determined by the presence of a distinct boundary plane, as well as by the inclusion features that were confined to the boundary and the shallow layer outside this boundary. The inclusion features observed within the interior region of the stones provided clear evidence of the natural origin of the corundum core (see, e.g., Gübelin and Koivula, 1986). The concentration of inclusions along the boundary plane revealing the outlines of crown and pavilion facets confirmed that the natural corundum used as the starting material was faceted.

Synthetic overgrowth on a natural seed is not new to gemology. Probably the best-known commercial product involved the growth of synthetic emerald onto a natural beryl host, first achieved by Lechleitner in 1959 (see, e.g., Gübelin, 1960-61; Bank, 1976; Schmetzer et al., 1981). However, Lechleitner also experimented with the same approach on corundum. For a review of the features noted for those samples, the reader is referred to Schmetzer and Bank (1988). In this well-illustrated article, the authors describe samples where Lechleitner had grown synthetic ruby on top of natural "pale to even colourless corundum seeds. ..." (p. 97). In many respects, the features described in

Figure 11. Turbid bluish white clouds confined to the overgrowth layer commonly displayed a distinctly mottled texture. Also note the multitude of pinpoint inclusions that were typically present throughout the overgrowth layer. Magnified 25x.

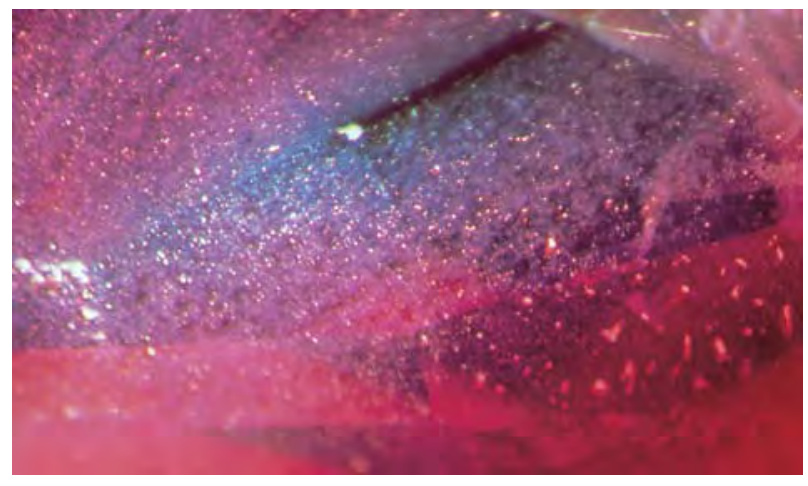

that paper are consistent with those observed in the present study. These include the presence of a sharp boundary between the natural corundum "seeds" and the synthetic ruby overgrowth, as well as two types of inclusions (i.e., those of the natural corundum seed and those of the synthetic ruby overgrowth).

However, there are some differences in the specific inclusion features noted for the synthetic ruby overgrowth. Schmetzer and Bank describe needlelike and doubly refractive inclusions, which were not observed in the present samples. Conversely, their article did not mention the presence of inclusions aligned along the boundary and turbid clouds within the overgrowth layers, which were typical of the present samples. The authors noted similar internal growth structures associated with the natural corundum host, but not the seemingly unique patterns observed with immersion, such as those that resembled a steep mountainside or the roiled appearance. The latter is somewhat similar to the internal growth features seen in hydrothermally grown synthetic rubies (see, e.g., Peretti and Smith, 1993), but closer inspection revealed distinct differences.

Although Schmetzer and Bank did not mention the chromium concentrations of their samples, they did detect molybdenum, which proves that Lechleitner was using a commercial flux method to grow the synthetic ruby layer. Molybdenum or other elements typical of commercial flux-growth

Figure 12. This $0.80 \mathrm{ct}$ sample was repolished to illustrate clearly how this naturally occurring healed fracture in the core extends up to, but not beyond, the boundary with the synthetic ruby overgrowth. Also note the sharp color demarcation between the essentially colorless natural corundum core and the deeply saturated synthetic ruby overgrowth layer. Magnified 25×.

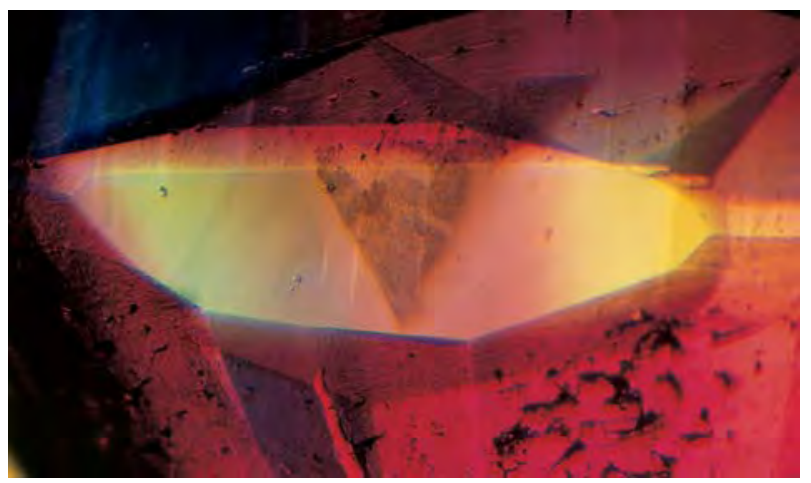


processes for synthetic rubies were not detected in the present study.

Although the present author was informed by one of the suppliers that the producer insisted these stones were "diffusion treated" and not a synthetic ruby overgrowth (J. Boyles, pers. comm., 1998), there is not sufficient information to determine the source of the overgrowth. It could have been produced by a commercial flux-growth process that used a flux involving elements that could not be detected by EDXRF (such as lithium). The absence

TABLE 1. Separation of red lattice diffusion-treated corundum from corundum with a synthetic ruby overgrowth.

\begin{tabular}{|c|c|}
\hline Synthetic ruby overgrowth & Red lattice diffusion treatment ${ }^{a}$ \\
\hline Inert to short-wave UV radiation & $\begin{array}{l}\text { Chalky bluish white to yellowish } \\
\text { white short-wave UV fluores- } \\
\text { cence, confined to the surface }\end{array}$ \\
\hline $\begin{array}{l}\text { Remnants of the outer "skin" of } \\
\text { the overgrowth layer, which } \\
\text { reveal traits characteristic of } \\
\text { crystal growth }\end{array}$ & $\begin{array}{l}\text { Whitish inclusions along the } \\
\text { surface resulting from damage } \\
\text { due to the treatment }\end{array}$ \\
\hline $\begin{array}{l}\text { Indentations at the surface } \\
\text { revealing characteristics of crystal } \\
\text { morphology; do not extend } \\
\text { beyond the boundary }\end{array}$ & $\begin{array}{l}\text { Etch pits and voids at the } \\
\text { surface, accompanied by } \\
\text { concentrations of diffused } \\
\text { color }\end{array}$ \\
\hline $\begin{array}{l}\text { A boundary plane at or just below } \\
\text { the surface }\end{array}$ & No boundary plane \\
\hline $\begin{array}{l}\text { Two sets of inclusions: (1) in the } \\
\text { natural corundum core, and (2) in } \\
\text { the synthetic overgrowth }\end{array}$ & $\begin{array}{l}\text { Inclusions typical of natural } \\
\text { corundum that may extend from } \\
\text { the interior to the surface }\end{array}$ \\
\hline $\begin{array}{l}\text { A high concentration of inclusions } \\
\text { aligned along the boundary plane, } \\
\text { often highlighting the facet arrange- } \\
\text { ment of the host gemstone }\end{array}$ & Nothing similar \\
\hline $\begin{array}{l}\text { Pinpoint inclusions that are con- } \\
\text { fined to a shallow depth and do } \\
\text { not extend past the boundary } \\
\text { plane }\end{array}$ & Nothing similar \\
\hline $\begin{array}{l}\text { Bluish white turbidity that is con- } \\
\text { fined to a shallow depth and } \\
\text { extends only to the boundary } \\
\text { plane or just beneath it }\end{array}$ & Nothing similar \\
\hline $\begin{array}{l}\text { A shallow red coloration that has } \\
\text { a sharp and distinct planar border } \\
\text { between the overgrowth layer and } \\
\text { the interior of the gemstone }\end{array}$ & $\begin{array}{l}\text { A shallow red coloration that } \\
\text { "bleeds" at the edges }\end{array}$ \\
\hline $\begin{array}{l}\text { Irregular or striated growth struc- } \\
\text { tures within the overgrowth layer }\end{array}$ & Nothing similar \\
\hline $\begin{array}{l}\text { An image of steep mountainside } \\
\text { "contours" visible with immersion } \\
\text { at the surface/contact plane of } \\
\text { the host gemstone with the } \\
\text { overgrowth }\end{array}$ & Nothing similar \\
\hline
\end{tabular}

a From McClure et al. (1993). of structurally bonded $\mathrm{OH}$ groups in the infrared spectrum precludes production of the synthetic overgrowth layer by any commercial hydrothermal, flame-fusion, Czochralski, or floating-zone synthetic growth method.

Alternatively, the layer could have been produced unintentionally in the course of an attempt at true lattice diffusion treatment that used an aluminumbased flux. Such a flux (containing significant amounts of $\mathrm{Cr}$ ) is proposed, because the faceted surface of the core natural corundum did not show any evidence of the surface dissolution that would have been needed to supply the alumina necessary for the volume of synthetic ruby that was subsequently grown. Nevertheless, we do know that when heattreatment techniques are used in combination with chemical additives (fluxes), processes similar to those that take place during the growth of synthetic rubies and/or sapphires may also occur. For example, as part of an ongoing research project into the heat treatment of corundum, the Gübelin Gem Lab heated natural rubies with a commercially available aluminum-silicate flux to try to heal fractures. This experiment resulted in the unexpected growth of a significant amount of synthetic corundum on the surface of the rubies heated with that particular flux. Recently, evidence of the deposition of synthetic materials, including corundum, was detected on the surface of samples of the "new" beryllium lattice diffusion-treated corundum, which also is produced in Thailand (see, e.g., http://www.agta.org/consumer/ gtclab/treatedsapps01.htm and Gem Trade Lab Notes, this issue, pp. 255-256).

At first glance, the patchy color concentrations of this material are consistent with its representation as "Diffusion Ruby." In fact, red lattice diffusion-treated corundum (as reported by McClure et al., 1993) and stones with a thin synthetic ruby overgrowth may have several traits and properties in common. These include:

- Shallow color concentration confined to the near-surface

- A patchy or uneven coloration, following the facet arrangement, viewed both with the unaided eye and with magnification over diffused light or, more markedly, with immersion

- OTL refractometer readings (i.e., >1.81)

- Elevated chromium concentrations

- Evidence of high-temperature alteration of inclusions 
However, on close inspection, a number of features will readily separate true red lattice diffusiontreated corundum from stones that owe their coloration to a thin overgrowth of synthetic ruby on top of natural corundum seeds (table 1).

Probably the single most diagnostic feature of the synthetic overgrowth is the aligned concentration of inclusions at the contact plane of the natural corundum core and the overgrowth layer. The location, orientation, and visual appearance of these aligned inclusions clearly demonstrates that they formed during the initial deposition of synthetic ruby, along the original polishing directions of the faceted natural "host." Repolishing/faceting of the stones after deposition of the synthetic overgrowth layer typically results in a non-uniform thickness of that layer and even its complete removal in some areas. In all of the samples examined to date, the facet arrangement of the core natural corundum was visible below the surface layer and did not correspond to the facet arrangement at the surface of the overgrowth (again, see figure 10).

The thickness (or absence) of the overgrowth layer had a significant effect on the properties recorded for these samples. On facets where the synthetic overgrowth was no longer present, normal R.I. readings for corundum were recorded. On facets where the overgrowth was very thin (less than approximately $0.1 \mathrm{~mm}$ ), the edges of the refractive indices were rather "fuzzy," as compared to the "sharp" edges normally observed. The facets with thicker overgrowth layers always displayed OTL R.I. readings. Elevated R.I. readings are consistent with corundum that contains higher than normal "trace element" concentrations (see, e.g., Webster, 1983; Peretti et al., 1995). And when chromium is significantly higher (as noted in red lattice diffusion-treated samples; McClure et. al., 1993), >1.81 readings also have been recorded previously.

Colorless to near-colorless natural sapphires were used as the "seeds" for this treatment, because they typically lack the trace-element concentrations necessary to impart color as a result of heat treatment. It is particularly important that the natural starting material contain low relative concentrations of tita- nium and iron so the host will not develop a distinct blue coloration during the heating process, thus producing an overall purple coloration once the synthetic ruby overgrowth is added. The orange color concentration in the interior of one sample is attributed to trapped-hole color centers associated with naturally occurring magnesium $\left(\mathrm{Mg}^{2+}\right)$ that were created during the heating/overgrowth process (see, e.g., Emmett and Douthit, 1993).

\section{CONCLUSIONS}

Red lattice diffusion-treated corundum was introduced in the early 1990s, so this author was not surprised when gems were being offered as "Diffusion Ruby" by a variety of gem dealers over the past few years. Indeed, there are a number of similarities between true red lattice diffusion-treated corundum and the samples offered as "Diffusion Ruby." These consist of patchy color concentrations from one facet to the next, high chromium concentrations, and OTL refractive index readings. However, these synthetic ruby overgrowths are readily distinguished by several traits, which include the presence of a boundary plane at the interface of the natural corundum core and the synthetic ruby overgrowth layer located just below (or sometimes reaching) the surface of the stone, as well as different inclusion features in the synthetic overgrowth layer as compared to the natural corundum seed. In addition, the synthetic overgrowth is inert to shortwave UV radiation.

Although synthetic ruby overgrowths on natural corundum were produced experimentally some 20 years ago, the description of colorless to near-colorless natural sapphires with a thin layer of synthetic ruby overgrowth seems particularly timely today when one considers the controversy surrounding the deposition of synthetic corundum in the course of the new beryllium lattice-diffusion treatment of corundum. As treatment techniques that incorporate fluxes in conjunction with high temperatures continue to develop and evolve, the distinction between natural, treated, and synthetic corundum may become increasingly difficult.

\section{REFERENCES}

Bank H. (1976) Mit synthetischem Smaragd überzogene natürliche farblose Berylle (nach Lechleitner). Zeitschrift der Deutschen Gemmologischen Gesellschaft, Vol. 25, No. 2, pp. 107-108.
Bank H. (1983) Neue synthetische Rubine nach Lechleitner als überzug auf natürlichen und synthetischen Rubinen sowie farblosen Korunden der Verneuilsynthese. Zeitschrift der Deutschen Gemmologischen Gesellschaft, Vol. 32, No. 4, p. 207. 
Emmett J.L., Douthit T.R. (1993) Heat treating the sapphires of Rock Creek, Montana. Gems «) Gemology, Vol. 29, No. 4, pp. 250-272.

Gübelin E.J. (1960-61) More light on beryls and rubies with synthetic overgrowth. Gems ↔) Gemology, Vol. 10, No. 4, pp. 105-113.

Gübelin E.J., Koivula J.I. (1986) Photoatlas of Inclusions in Gemstones. ABC Edition, Zurich, Switzerland.

Hänni H.A., Kiefert L., Chalain J.-P., Wilcock I.C. (1996) Ein Renishaw Raman Mikroskop im gemmologischen Labor: Erste Erfahrungen bei der Anwendung. Zeitschrift der Deutschen Gemmologischen Gesellschaft, Vol. 45, No. 2, pp. 55-70.

Hughes R.W. (1996) Ruby and Sapphire. RHW Publishing, Boulder, CO.

Hurlbut C.S., Kammerling R.C. (1991) Gemology, 2nd ed. Wiley Interscience, New York.

Kane R.E., Kammerling R.C., Koivula J.I., Shigley J.E., Fritsch E. (1990) The identification of blue diffusion-treated sapphires. Gems $\oplus$ Gemology, Vol. 26, No. 2, pp. 115-133.

Kiefert L., Schmetzer K. (1991) The microscopic determination of structural properties for the characterization of optical uniaxial natural and synthetic gemstones, Part 1: General considerations and description of the methods. Journal of Gemmology, Vol. 22, No. 6, pp. 344-354.

Liddicoat R.T. (1989) Handbook of Gem Identification, 12th ed. Gemological Institute of America, Santa Monica, CA.

McClure S.F., Kammerling R.C., Fritsch E. (1993) Update on diffusion-treated corundum: Red and other colors. Gems \&)
Gemology, Vol. 29, No. 1, pp. 16-28

Peretti A., Schmetzer K., Bernhardt H-J., Mouawad F. (1995) Rubies from Mong Hsu. Gems «) Gemology, Vol. 31, No. 1, pp. 2-26.

Peretti H.A., Smith C.P. (1993) A new type of synthetic ruby on the market: Offered as hydrothermal synthetic rubies from Novosibirsk. Australian Gemmologist, Vol. 18, No. 5, pp. 149-156.

Schmetzer K. (1986) An improved sample holder and its use in the distinction of natural and synthetic ruby as well as natural and synthetic amethyst. Journal of Gemmology, Vol. 20, No. 1 , pp. 20-33.

Schmetzer K., Bank J. (1988) Lechleitner synthetic rubies with natural seed and synthetic overgrowth. Journal of Gemmology, Vol. 21, No. 2, pp. 95-101.

Schmetzer K., Bank H., Stähle V. (1981) The chromium content of Lechleitner synthetic emerald overgrowth. Gems et Gemology, Vol. 17, No. 2, pp. 98-100.

Smith C.P. (1995) A contribution to understanding the infrared spectra of rubies from Mong Hsu, Myanmar. Journal of Gemmology, Vol. 24, No. 5, pp. 321-335.

Smith C.P. (1996) Introduction to analyzing internal growth structures: Identification of the negative $d$ plane in natural ruby. Gems 4 Gemology, Vol. 32, No. 3, pp. 170-184.

Webster R. (1983) Gems: Their Sources, Descriptions and Identification, 4th ed. Butterworths, London, UK.

Williams K.P.J., Nelson J., Dyer S. (1997) The Renishaw Raman database of gemological and mineralogical materials. Issue 2, England.

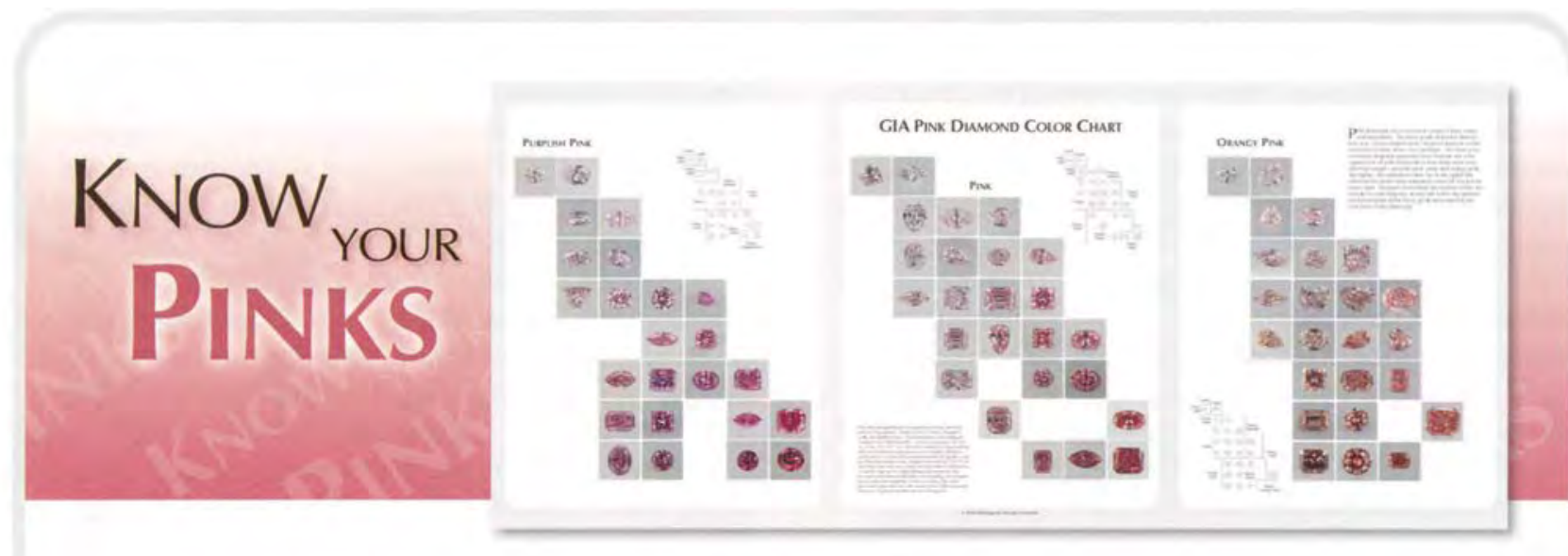

How well do you really know pink diamonds? GEMS \& GEMOLOGY offers the ultimate must-have reference. The pink diamond foldout chart from the Summer 2002 issue, illustrating a broad range of fancy color grades, is now available as an attractive laminated wall poster for just \$14 (\$18 outside the U.S.).

To order, visit our web site, www.gia.edu/gandg and click on How to Order, or contact Subscriptions Manager Debbie Ortiz at (800) 421-7250, ext. 7142 . Outside the U.S. and Canada, call (760) 603-4000, ext.7142. Oremail dortiz@gia.edu.
The information you needwhen you need it. 